\title{
Respectful focused antenatal care and associated factors among pregnant women who visit Shashemene town public hospitals, Oromia region, Ethiopia: a cross-sectional study
}

\author{
Daniel Adane ${ }^{1 *} \mathbb{D}$, Agegnehu Bante $^{3}$ and Biresaw Wassihun ${ }^{2}$
}

\begin{abstract}
Background: Focused antenatal care is the most significant and inclusive care given to pregnant women to promote and maintain the optimal health of the mother and the fetus. Providing respectful care during focused antenatal care is believed to be the most important cost-effective interventions to increase maternity service utilization. Therefore, this study was aimed to assess respectful focused antenatal care and associated factors among pregnant women who visit Shashemene town public hospitals, Oromia region, Ethiopia, 2019.

Methods: Institution-based cross-sectional study was conducted from July-August, 2019. A total of 423 pregnant mothers were selected using a systematic sampling technique. Data were collected using structured and pre-tested interviewer-administered questionnaires. Data entry and analysis were made using Epi Info version ${ }^{\mathrm{TM}} 7$ and Statistical Package for Social Science (SPSS) version 24.0 respectively. Both bivariate and multivariate logistic regression analyses were used to identify associated factors. Statistical significance was declared at a $p$ value of $<0.05$ with a $95 \%$ confidence level.

Results: A total of 420 women have participated in the study, making a response rate of $99.5 \%$. About $63 \%$ of participants received respectful care during focused antenatal care. Having no formal education $[A O R=8.3(95 \% \mathrm{Cl}$ 9.85-17.47)], low average monthly income $[A O R=3.16(95 \% \mathrm{Cl} 1.52-6.57)]$, having unplanned pregnancy $[A O R=9.90$ $(95 \% \mathrm{Cl} 3.48-8.16)]$ and being multigravida $[\mathrm{AOR}=8.82(95 \% \mathrm{Cl} 2.90-6.80)]$ were significantly associated with respectful focused antenatal care.

Conclusions: The study findings indicate that respondents' respectful focused antenatal care is mainly affected by educational level, average family monthly income, having an unplanned pregnancy, and gravidity. Providing acceptable, quality, and honorable care for all women regardless of educational status, family income, and status of pregnancy is very crucial to entice more mothers to the health facility.
\end{abstract}

Keywords: Focused antenatal care, Respectful care, Ethiopia

*Correspondence: danieladane178@yahoo.com

${ }^{1}$ Department of Midwifery, College of Medicine and Health Sciences,

Wolkite University, Wolkite, Ethiopia

Full list of author information is available at the end of the article

\section{Background}

Improving maternal health is one of the recommendations to achieve the global target of sustainable development goals (SDGs) for the reduction of maternal mortality to less than 70 out of 100,000 live births [1]. Worldwide maternal morbidity and mortality have still been continued to be the major public health problems 
[2]. Globally, approximately three million women died from pregnancy and childbirth-related complications. Of these, all most all (99\%) maternal death occurs in Lowand middle-income countries and nearly two-thirds (66\%) of maternal deaths are more prevalent in subSaharan African countries [3]. In Ethiopia, the maternal mortality ratio was 412/100,000 live births [2, 4]. According to the Ethiopian demographic health survey (EDHS) 2016, the utilization of antenatal care (ANC) and skilled delivery were found to be $62 \%$ and $26 \%$ respectively. One of the main reasons for the low utilization of maternity services was disrespect and abuse by caregivers [5].

Pregnancy is an important event from both social and medical points of view but its related complications were a major cause of maternal death [6]. Obstetric abuse during antenatal care is one of the contributing factors for low maternal health care service utilization [7]. Antenatal care (ANC) is care given to pregnant women to promote and maintain optimal health of the mother and fetus throughout the pregnancy, labor, and puerperium [8]. A lack of respectful care during ANC visit is one indicator of poor quality of care [9]. Focused antenatal care (FANC) stated that every pregnant woman is at risk, so providing FANC is a good opportunity to identify preexisting and newly occurring diseases [2].

Respectful maternity care (RMC) is crucial to the health, wellbeing, and survival of women and newborns and it is also very important to fascinate more mothers to the health facilities $[7,10]$. Although FANC is effective and has been widely promoted, data on respectful maternity care during focused antenatal care in study setting is limited; therefore this study was aimed to assess the level of respectful focused antenatal care and associated factors among pregnant women who visit Shashemene town public hospitals, Oromia region, Ethiopia.

\section{Methods}

\section{Study design, setting, and subjects}

An institution-based cross-sectional study was conducted in Shashemene town public hospitals from JulyAugust 2019. Shashemene is located in the central part of the Oromia region, 248 kilometers far from Addis Ababa (the capital city of Ethiopia). The town has a total population of 218,335 from this nearly half $(48.9 \%)$ of them were females. It consists of peoples with different languages, more than 18 ethnic groups, and foreigners like the Ras Teferian community. All pregnant women who were found in Shashemene town were the source population whereas all pregnant women who were attending ANC service in each hospital during the study period were taken as the study population. The town has two hospitals that provide ANC services and both hospitals were included in this study. The study populations were proportionally allocated to each hospital based on the average number of clients who received antenatal care services (279 from Kuyera Hospital and 144 from Melka odda Hospital).

\section{Sample size determination and techniques}

The minimum sample size was determined using a single population proportion formula and it was calculated using Epi Info ${ }^{\mathrm{TM}}$ version 7 based on the following assumptions. An estimated level of respectful and abuse-free maternity care during antenatal care $50 \%(\mathrm{P}=0.5), 95 \%$ confidence level, and a margin error to be $5 \%(\mathrm{~d}=0.05)$ and $10 \%$ non-response rate. The final sample size was therefore calculated to be 423 pregnant mothers. A systematic random sampling technique was used to select sampled pregnant mothers that represent the entire hospital. The interval, $\mathrm{K}=4$, was calculated by dividing the total number of ANC follow up mothers based on those mothers who received antenatal care services at each health facility in the month proceeding the data collection period. Then the first client was selected by simple random sampling among the first four antenatal care followers in the sampling frame. The data collection was begun after informing the related local authorities about the objectives of the study. Data collectors were worked with doctors and midwives in the ANC outpatient wards every day until the desired sample sizes were achieved. Every 4th pregnant mothers who come to ANC outpatient departments (OPDs) for routine antenatal care follow-ups were selected in each hospital. After informing and obtaining informed written consent, the trained data collectors interviewed eligible and randomly selected mothers in each ANC ward.

\section{Data collection and measurements}

A structured and pre-tested interviewer-administered questionnaire was prepared by reviewing relevant works of different literature. The tool was adopted and modified into the local context from previously published articles, and WHO guidelines. Four experienced BSc midwives and two supervisors were recruited and trained for data collection and supervision, respectively. The questions were classified into socio-demographic characteristics, obstetric history, and respectful related items. Data were collected through the face-to-face interview method. The supervisors and principal investigators supervised the process of data collection daily. Respondents who responded correctly (yes) at least $\geq 10$ questions from 15 respectful items were considered as having respectful care, whereas those respondents who have reported at least two "No" questions from 15 respectful items were considered as having no respectful care. The values of respectful FANC were coded as " $1=$ Correct response 
(consistent with respectful components) and $0=$ Incorrect response (inconsistent with respectful care components)". Finally, a composite variable from these questions was generated to categorize pregnant women as having "respectful care/abusive care.

To ensure quality, the questionnaire was translated into the local language by experts. Finally, before data collection, it was re-translated back to English to verify consistency. Before starting the actual data collection, one day of extensive training was given for the data collectors and supervisors. A pre-test for appropriateness and feasibility of the tool was conducted and all necessary modifications and amendments were done accordingly. The tool was used with a reliability test or Cronbach's alpha correlation coefficient of greater than or equal to 0.7 for inter-item consistency. The data collection team was communicated and discussed with principal investigators if they face any challenges during the data collection period daily. After data collection before analysis, all collected data were checked for completeness.

\section{Statistical analyses}

Data were coded, cleaned, edited, and entered into Epi Info version ${ }^{\mathrm{TM}} 7$ and exported to SPSS version 24.0 for statistical analysis. The presence of an association between explanatory and outcome variables was ascertained using binary logistic regression analysis. The goodness of fit was tested by the log-likelihood ratio (LR). To control all possible confounders all variables with $\mathrm{P}<0.2$ in the bivariate analysis were included in the final model of multivariable analysis. To see the correlation between independent variables Multi-collinearity test was carried out by using collinearity statistics. In a multivariable model adjusted odds ratio determined with a 95\% confidence level was used to assess the strength of association. In this study $p$ value $<0.05$ was deemed to declare statistical significance. Then, the finding was presented by using simple frequencies, summary measures, tables, texts, and figures.

\section{Results}

\section{Socio-demographic characteristics of respondents}

In this study, a total of 420 respondents have participated with a response rate of $99.5 \%$. The mean age of study participants was 25.8 ( $\mathrm{SD} \pm 3.7$ years). More than half, 224 (53.3\%) of respondents were in the age group of 26-30 years. Two hundred thirty-three $(55.5 \%)$ were orthodox Christian religious followers. One hundred ninety-four (46.2\%) of the respondents had a formal education, and $56.0 \%$ of the respondents have been working as a housewife (Table 1).

\section{Obstetric characteristics of respondents}

Nearly half $(49.8 \%)$ of respondents were Primiparous and the majority $(96.7 \%)$ of the respondents had a history of antenatal care (ANC) follow-up. Four hundred six (96.7\%) of respondents had supported/planned pregnancy. More than three-fifth $(62.6 \%)$ of the respondents had a previous history of institutional delivery and $90.4 \%$ of respondents have planned to give birth in health facilities (Table 2).

\section{Prevalence of respectful focused antenatal care}

Three hundred ninety-two (93.3\%) of respondents reported that health care providers were explained procedures by giving greetings before the examination. Nearly half (46.7\%) of respondents experienced obstetric violence/abuse during focused antenatal care counseling on birth preparedness and complication readiness plan and 139 (33.1\%) of respondents reported that their waiting time for examination was not fair (Table 3). About $37 \%$ of respondents reported having experienced at least one form of abuse during focused antenatal care (Fig. 1).

\section{Factors associated with respectful focused antenatal care}

The result of multivariate analysis showed that respondent's level of education, the status of pregnancy, gravidity, and average family monthly income were some of the factors associated with respectful focused antenatal care at $p$ value $<0.05$.

Respondents who had no formal education were 8.3 $[\mathrm{AOR}=8.3(95 \% \mathrm{CI} 9.15-17.47)]$ times more likely to experience abuse during FANC than those respondents who have an educational level of collage and above. Similarly, respondents who had educational levels of primary and secondary were $2.45[\mathrm{AOR}=2.45(95 \% \mathrm{CI} 1.07-5.62)]$ times more likely to experience abuse during FANC than those respondents who had an educational level of collage and above.

Respondents who had an average family monthly income of less than or equal to 3000 Ethiopia birr were $3.16[\mathrm{AOR}=3.16(95 \% \mathrm{CI} 1.52-6.57)]$ times more likely to experienced abuse during FANC as compared to those respondents who had an average family monthly income of greater than 3000 Ethiopian birrs. Respondents who had unplanned pregnancies were $9.9[\mathrm{AOR}=9.90(95 \% \mathrm{CI}$ 3.48-8.16)] times more likely to experience violence during FANC as compared to those respondents who had planned pregnancy. Respondents who had multigravida were $8[\mathrm{AOR}=8.82(95 \% \mathrm{CI} 2.90-6.80)]$ times more likely to have reported abuse during FANC than those respondents who had primigravida (Table 4). 
Table 1 Socio-demographic characteristics of respondents at Shashemene town hospitals, $2019(n=420)$

\begin{tabular}{|c|c|c|c|}
\hline Variables & Category & Frequency & Percentage \\
\hline \multirow[t]{3}{*}{ Age } & $20-25$ & 181 & 43.1 \\
\hline & $26-30$ & 224 & 53.3 \\
\hline & $31-35$ & 15 & 3.6 \\
\hline \multirow[t]{4}{*}{ Marital status } & Married & 370 & 87.7 \\
\hline & Divorced & 19 & 4.5 \\
\hline & Widowed & 20 & 4.7 \\
\hline & Single & 11 & 2.6 \\
\hline \multirow[t]{3}{*}{ Religion } & Orthodox & 233 & 55.5 \\
\hline & Muslim & 73 & 17.4 \\
\hline & Protestant & 114 & 27.1 \\
\hline \multirow[t]{4}{*}{ Ethnicity } & Oromo & 310 & $73.8 \%$ \\
\hline & Amhara & 90 & $21.4 \%$ \\
\hline & Tigre & 8 & $1.9 \%$ \\
\hline & Wolyita and Sidama & 12 & $2.9 \%$ \\
\hline \multirow[t]{5}{*}{ Occupation } & Housewife & 235 & 56.0 \\
\hline & Private employee & 15 & 3.6 \\
\hline & Government employee & 84 & 20.0 \\
\hline & Merchants & 57 & 13.6 \\
\hline & Daily workers & 29 & 6.9 \\
\hline \multirow[t]{2}{*}{ Residence } & Urban & 227 & 54.0 \\
\hline & Rural & 193 & 46.0 \\
\hline \multirow[t]{4}{*}{ Educational status of mothers } & No formal education & 194 & 46.2 \\
\hline & Primary $(1-8)$ & 58 & 13.8 \\
\hline & Secondary (9-12) & 42 & 10.0 \\
\hline & Collage and above & 126 & 30.0 \\
\hline \multirow[t]{3}{*}{ Husbands educational status } & No formal education & 99 & 23.6 \\
\hline & Primary and secondary & 122 & 29.0 \\
\hline & Collage and above & 199 & 47.4 \\
\hline \multirow[t]{2}{*}{ Average family monthly income } & $<3000$ birr & 237 & 56.4 \\
\hline & $\geq 3000$ birr & 183 & 43.6 \\
\hline \multirow[t]{2}{*}{ Family size } & $1-3$ & 157 & 37.4 \\
\hline & $>3$ & 263 & 62.6 \\
\hline
\end{tabular}

\section{Discussion}

This study was conducted to assess respectful focused antenatal care and associated factors among pregnant women who visit Shashemene town public hospitals, Oromia Ethiopia; we found that $37 \%$ of participants were committed abusive care during antenatal care. This finding suggests that health care providers should take into account the potential risk of abuse while assessing clinical health assessment during antenatal care visits, childbirth, and post-natal visits of a woman. Besides, for healthcare planners this is vital. This knowledge can be used to build relevant programs, channeling scarce resources to teaching what is needed as opposed to imparting messages that are already known. This level of abusive care during antenatal care is higher than what is reported from a study done elsewhere in Ethiopia [14, 15]. The discrepancy of these findings might be attributed to the difference in method used and study settings, socio-demographic characteristics of the study participants, and the availability and accessibility of the health services infrastructures. On the other hand; the report in this study implies that there is a lack of balance that the zone health office and regional health bureau could work in collaboration with the local health caregiver to lessen the abusive care of women during antenatal care.

This finding was lower than the study conducted in Enugu Nigeria, Pakistan, and other parts of Ethiopia [11-13]. This difference can be explained by the difference in the background of the study participants and the time gap. In addition to this, the health system-related 
Table 2 Obstetric characteristics of respondents at Shashemene town hospitals, $2019(n=420)$

\begin{tabular}{|c|c|c|c|}
\hline Variables & Category & Frequency & Percentage \\
\hline \multirow[t]{2}{*}{ Gravidity } & Prima- gravid & 114 & 27.1 \\
\hline & Multi gravid & 306 & 71.9 \\
\hline \multirow[t]{2}{*}{ Parity } & Primiparous & 209 & 49.8 \\
\hline & Multiparous & 211 & 50.2 \\
\hline \multirow[t]{2}{*}{ History of abortion } & Yes & 20 & 4.8 \\
\hline & No & 400 & 95.2 \\
\hline \multirow[t]{2}{*}{ History of stillbirth } & Yes & 14 & 3.3 \\
\hline & No & 406 & 96.7 \\
\hline \multirow[t]{2}{*}{ The previous history of antenatal care follow up } & Yes & 406 & 96.7 \\
\hline & No & 14 & 3.3 \\
\hline \multirow[t]{4}{*}{ Frequency of current antenatal care visit } & $1 s t$ & 45 & 10.7 \\
\hline & $2 n d$ & 200 & 47.6 \\
\hline & $3 r d$ & 147 & 35.0 \\
\hline & 4th & 28 & 6.7 \\
\hline \multirow[t]{2}{*}{ Pregnancy status } & Planned & 406 & 96.7 \\
\hline & Unplanned & 14 & 3.3 \\
\hline \multirow[t]{2}{*}{ History of health facility delivery } & Yes & 263 & 62.6 \\
\hline & No & 157 & 37.4 \\
\hline \multirow[t]{2}{*}{ Do you have a plan to give birth in a health facility's } & Yes & 380 & 90.4 \\
\hline & No & 40 & 9.6 \\
\hline \multirow[t]{4}{*}{ If no why $(n=40)$} & Home is better & 20 & 50.0 \\
\hline & Fear of health care providers & 8 & 20.0 \\
\hline & Not satisfied with antenatal care & 5 & 12.5 \\
\hline & No reason & 7 & 17.5 \\
\hline
\end{tabular}

Table 3 Prevalence of respectful focused antenatal care at Shashemene town hospitals, $2019(n=420)$

\begin{tabular}{|c|c|c|}
\hline Respectful/client-centered items during the focused antenatal care visit & Yes & No \\
\hline Did the health care provider respect your culture and religion during the general examination & $392(93.3)$ & $28(6.7)$ \\
\hline Did the health care provider explain procedures by giving a greeting before the examination & $392(93.3)$ & $28(6.7)$ \\
\hline Did the health care provider treated you in a friendly manner & $378(90)$ & $42(10)$ \\
\hline Did the Health care provider showed his/her concern and empathy & $392(93.3)$ & $28(6.7)$ \\
\hline Did the Health care provider explained types of laboratory investigation in a satisfactory way & $378(90)$ & $42(10)$ \\
\hline Did health care provider caring for you with a kind approach by calling your name & $406(96.7)$ & $14(3.3)$ \\
\hline $\begin{array}{l}\text { Did the health care provider responded to your needs whether or not you asked during counseling on birth } \\
\text { preparedness and complication readiness }\end{array}$ & $224(53.3)$ & $196(46.7)$ \\
\hline Did the health care provider assured your privacy during the examination & $364(86.7)$ & $56(13.3)$ \\
\hline Was waiting time fair for examination. & $281(66.9)$ & $139(33.1)$ \\
\hline Did the health care provider treated you compassionately and respectfully during ANC follow up & $350(83.3)$ & $70(16.7)$ \\
\hline Were you involved in decision making as much as you want & $334(79.5)$ & $86(20.5)$ \\
\hline Did you have well informed and good communication with the staffs & $393(93.6)$ & $27(6.4)$ \\
\hline Did you received individualized care during the ANC visit & $407(96.9)$ & $13(3.1)$ \\
\hline Did health care provider promotes partner/accompany during ANC & $379(90.2)$ & $41(9.8)$ \\
\hline Are you happy with all the services you have got today & $351(83.6)$ & $69(16.4)$ \\
\hline
\end{tabular}

factors might contribute to this difference due to the extensive work of health extension workers and various health care institutions in awareness creation about the drawback of abusive care in the study area. The other possibilities might be due to the difference in socio-economic and study participants since the previous study 


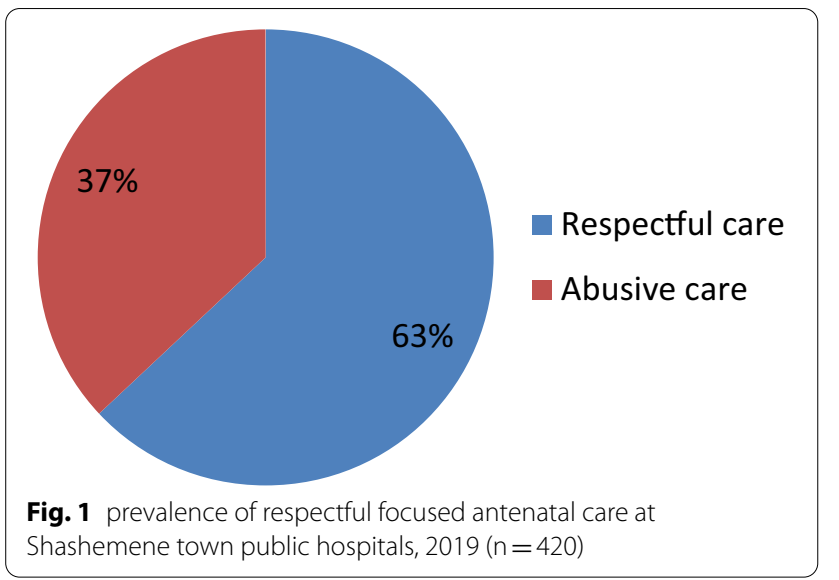

Fig. 1 prevalence of respectful focused antenatal care at Shashemene town public hospitals, $2019(n=420)$ was conducted among laboring mothers where labor pain by itself may make the mother not perceive whether they were respected or not at the time of pain. The finding implies that there is crated platform for maternity care providers that could help them to be aware of local values, beliefs, and traditions to anticipate and meet the needs of women, gain their trust and work with them.

In this study, we have found some factors associated with abusive care during the antenatal period.

These included having no formal education, low average monthly family income, having an unplanned pregnancy, and being multigravida. Respondents who had no formal education were almost 8 times more likely to experience abuse during FANC than those respondents who had an educational level of college and above. Similar studies conducted in Ethiopia have found that education level is an important factor of abusive care during

Table 4 Factors associated with respectful focused antenatal care at Shashemene town hospitals, 2019

\begin{tabular}{|c|c|c|c|c|}
\hline & \multicolumn{2}{|c|}{ Abuse during FANC } & \multirow[t]{2}{*}{ COR } & \multirow[t]{2}{*}{ AOR } \\
\hline & Yes & No & & \\
\hline \multicolumn{5}{|l|}{ Age } \\
\hline $20-25$ & 152 & 29 & 1 & 1 \\
\hline $26-30$ & 155 & 69 & $2.33(1.43-3.80)^{*}$ & $3.97(1.73-9.12)$ \\
\hline$\geq 31$ & 9 & 6 & - & - \\
\hline \multicolumn{5}{|l|}{ Mothers level of education } \\
\hline No formal education & 137 & 57 & $3.62(1.88-6.94)^{*}$ & $8.3(9.15-17.47)^{*}$ \\
\hline Primary and secondary & 72 & 28 & $3.38(1.64-6.95)^{*}$ & $2.45(1.07-5.62)^{*}$ \\
\hline College and above & 113 & 13 & 1 & 1 \\
\hline \multicolumn{5}{|c|}{ Average family monthly income } \\
\hline$\leq 3000$ & 195 & 42 & 1 & 1 \\
\hline$>3000$ & 127 & 56 & $2.04(1.29-3.24)^{*}$ & $3.16(1.52-6.57)^{*}$ \\
\hline \multicolumn{5}{|l|}{ Family size } \\
\hline $1-3$ & 129 & 28 & 1 & 1 \\
\hline$>3$ & 193 & 70 & $1.67(1.02-2.73)^{*}$ & $0.16(0.63-0.43)$ \\
\hline \multicolumn{5}{|l|}{ Residency } \\
\hline Urban & 171 & 56 & 1 & 1 \\
\hline Rural & 151 & 42 & $1.17(0.75-1.85)$ & $0.12(0.04-0.31)$ \\
\hline \multicolumn{5}{|l|}{ Status of pregnancy } \\
\hline Planned & 308 & 80 & 1 & 1 \\
\hline Unplanned & 14 & 18 & $4.95(2.36-10.38)^{*}$ & $9.90(3.48-8.16)^{*}$ \\
\hline \multicolumn{5}{|l|}{ History of abortion } \\
\hline Yes & 28 & 5 & 1 & 1 \\
\hline No & 293 & 93 & $1.71(0.66-4.72)$ & $0.98(0.14-6.65)$ \\
\hline \multicolumn{5}{|l|}{ History of stillbirth } \\
\hline Yes & 29 & 5 & 1 & 1 \\
\hline No & 293 & 93 & $1.84(0.69-4.89)$ & $4.72(0.67-12.95)$ \\
\hline \multicolumn{5}{|l|}{ Gravidity } \\
\hline Primgravida & 100 & 14 & 1 & 1 \\
\hline Multigravida & 222 & 14 & $2.70(1.46-4.99)^{*}$ & $8.82(2.90-6.80)^{*}$ \\
\hline
\end{tabular}

*Significant with $\mathrm{P}<0.05$ 
antenatal care [14]. This might be explained as women who did not attend formal education could not easily understand the drawback of abusive care on the health of the women themselves. Moreover, women who had no formal education will not have better awareness, understanding of birth preparedness, and complication readiness plan which was informed by health care providers.

Respondents who had an average family monthly income of less than or equal to 3000 Ethiopian birrs were almost 3 times more likely to experienced abuse care during FANC as compared to those respondents who have a family monthly income of greater than 3000 Ethiopian birrs. This finding is consistent with the study conducted in other parts of Ethiopia [12]. This might be because those women who had low average monthly income will not have better access/contact with the healthcare provider in the health facility within the recommended ANC period. Which in turn the women will not have information about the effect of abusive care on the health of the women themselves and their infants in the mother to child health $(\mathrm{MCH})$ clinic; these delaines may make themselves not to be respected secondary to dissatisfaction. Similarly, those respondents who had unplanned pregnancies were almost 10 times more likely to experience violence during focused antenatal care than those respondents who had planned pregnancies. This might be due to unplanned pregnancy might not be usually supported; as a result of this, pregnant women might not be respected by their partners and they will not receive early and adequate prenatal care than those with planned pregnancy.

\section{Limitation}

This study was a cross-sectional study and may not show the cause and effect relationship. The other limitation could be a small sample that might lead to statistical imprecision. We also didn't find sufficient data to compare and contrast respectful focused antenatal care with others, so it makes our discussion shallow.

\section{Conclusions}

This study depicted that the prevalence of abusive focused antenatal care was $63 \%$. Having no formal education, low family monthly income, having an unplanned pregnancy, and being multigravida were some of the factors associated with respectful focused antenatal care, so health care providers should treat all maternity care users regardless of maternal educational status and economic background. Besides providing respectful, individualized, and client-centered care for all women at every contact is very important to attract more mothers to the health facility.

\section{Supplementary Information}

The online version contains supplementary material available at https://doi. org/10.1186/s12905-021-01237-0.

Additional file 1. Qustionery.

\section{Abbreviations}

ANC: Antenatal care; AOR: Adjusted odds ratio; Cl: confidence interval; FANC: Focused antenatal care; SPSS: Statistical package for social sciences.

\section{Acknowledgements}

The authors would like to thank Arbaminch University and Shashemene town administrative for allowing ethical clearance and giving permission letters to do this research.Our gratitude goes to data collectors and the study participants.

\section{Authors' contributions}

All authors involved in the conception of the study and design, DA: Conceives the research idea, proposal development, supervised data collection process, conduct the analysis, and wrote the manuscript. BW: involved in proposal development, data analysis, and wrote the manuscript. AB: involved in data analysis, result in writing, and wrote the manuscript. All authors read and approved the final manuscript.

\section{Funding}

The authors have not declared a specific grant for this research from any funding agency in the public, commercial or not-for-profit sectors.

\section{Availability of data and materials}

The full data set and other materials about this study can be obtained from the corresponding author on reasonable request.

\section{Declarations}

\section{Ethics approval and consent to participate}

Ethical clearance for the study was obtained from the ethical review committee, Arbaminch University College of Health and Medical Science. An official letter was sent to the West Arsi zone health office and the data collection was begun after obtaining a written permission and cooperation letter to all hospitals on which the study was carried out. The study purpose, procedure, and duration, rights of the respondents and data safety issues, possible risks and benefits of the study were clearly explained to each participant using the local language. Then before the commencement of the study, all subjects gave their informed written consent. Participation in this study was purely voluntary and there was no monetary gain. The antenatal mothers were expected to be free to withdraw from the study without any penalty. No compensation was offered for participation in the study. All the participants' response was kept confidential by using the information only for the study and storing the study in a closed file.

\section{Consent to publications}

Not applicable.

\section{Competing interests}

The authors declare that they have no competing interests.

\section{Author details}

${ }^{1}$ Department of Midwifery, College of Medicine and Health Sciences, Wolkite University, Wolkite, Ethiopia. ${ }^{2}$ Department of Midwifery, College of Medicine and Health Sciences, Arbaminch University, Arbaminch, Ethiopia. ${ }^{3}$ Department of Nursing, College of Medicine and Health Sciences, Arbaminch University, Arbaminch, Ethiopia.

Received: 14 November 2019 Accepted: 22 February 2021

Published online: 04 March 2021 


\section{References}

1. Secretariat C. Ensure healthy lives and promote well-being for all, at all ages (SDG 3). 2017

2. Organization WH. Levels and Trends in Child Mortality: Report 2015: Estimates Developed by the UN Inter-Agency Group for Child Mortality Estimation (IGME). New York: United Nations Children's Fund; 2015.

3. WHO, U, UNFPA. World Bank Group, and the United Nations Population Division. Trends in maternal mortality: 1990 to 2015. Estimates by WHO, UNICEF. 2015.

4. WH Organization, Unicef, UNFPA/World Bank. Trends in maternal mortality: 1990 to 2008. WHO: Geneva; 2010

5. Ethiopia E, Demographic, Health Survey. 2016. 2012: ICF International, central Statistical Agency, July 2017.

6. Organization WH. WHO recommendations on antenatal care for a positive pregnancy experience: World Health Organization; 2016.

7. Freedman LP, Kruk ME. Disrespect and abuse of women in childbirth: challenging the global quality and accountability agendas. Lancet. 2014:384(9948):e42-4.

8. Lincetto O, Mothebesoane-Anoh S, Gomez P, Munjanja S. Antenatal care. In: Opportunities for Africa's newborns: practical data, policy and programmatic support for newborn care in Africa. 2006, p. 55-62.

9. Council RMCA. White ribbon alliance for safe motherhood (2011). Respectful maternity care: the universal rights of childbearing women Washington, DC. WRA Retrieved (August 8th, 2013), p. 1-6.
10. Reed R, Sharman R, Inglis C. Women's descriptions of childbirth trauma relating to care provider actions and interactions. BMC Pregnancy Childbirth. 2017;17(1):21.

11. Okafor II, Ugwu EO, Obi SN. Disrespect and abuse during facilitybased childbirth in a low-income country. Int J Gynecol Obstet. 2015;128(2):110-3.

12. Gebremichael MW, Worku A, Medhanyie AA, Berhane Y. Mothers' experience of disrespect and abuse during maternity care in northern Ethiopia. Global Health Action. 2018;11(1):1465215.

13. Azhar Z, Oyebode O, Masud H. Disrespect and abuse during childbirth in district Gujrat, Pakistan: a quest for respectful maternity care. PloS ONE. 2018:13(7):e0200318

14. Asefa A, Bekele D. Status of respectful and non-abusive care during facility-based childbirth in a hospital and health centers in Addis Ababa,\&nbsp;Ethiopia. Reprod Health. 2015;12(1):33.

15. Nawab T, Erum U, Amir A, Khalique N, Ansari MA, Chauhan A. Disrespect and abuse during facility-based childbirth and its sociodemographic determinants-A barrier to healthcare utilization in rural population. J Family Med Primary care. 2019;8(1):239.

\section{Publisher's note}

Springer Nature remains neutral with regard to jurisdictional claims in published maps and institutional affiliations.
Ready to submit your research? Choose BMC and benefit from:

- fast, convenient online submission

- thorough peer review by experienced researchers in your field

- rapid publication on acceptance

- support for research data, including large and complex data types

- gold Open Access which fosters wider collaboration and increased citations

- maximum visibility for your research: over $100 \mathrm{M}$ website views per year

At BMC, research is always in progress.

Learn more biomedcentral.com/submissions 